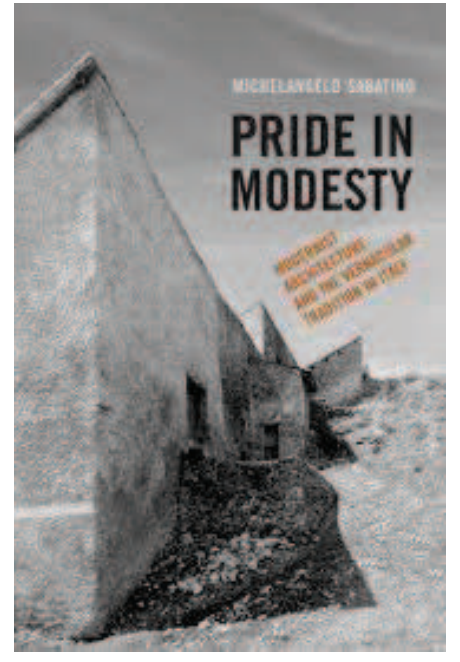

PRIDE IN MODESTY:

MODERNIST ARCHITECTURE AND THE VERNACULAR TRADITION IN ITALY

Sabatino, Michelangelo. Toronto: University of Toronto Press, 20i I

Joana Cunha Leal

\title{
is
}

${ }^{1} \mathrm{E}$, por extensão, original e cópia, vanguarda e retaguarda etc.

\section{Arquitectura Vernacular e o brilho do MODERNISMO IMPURO}

A história da arte e da arquitectura, incluindo a história do modernismo, vem insistindo numa lógica de classificação da produção artística severamente compartimentada. Os princípios dessa arrumação foram, e continuam a ser, predominantemente estilísticos. Implicam por isso o recurso a uma sucessão de classificações previamente estabelecidas - renascimento, maneirismo, barroco, e no caso da história do modernismo: impressionismo, fauvismo, futurismo, expressionismo etc.-, imutáveis e putativamente clarificadoras, que só muito raramente são postas em causa. Estas classificações forjam uma história sequencial, ao mesmo tempo em que padronizam as possibilidades e as expectativas admitidas para cada intervalo cronológico-estilístico. Essa padronização foi desenhada a partir das "obras-chave" dos grandes centros de produção artística e diz invariavelmente respeito à arte erudita (high). É por esta via que a legitimidade do que se classifica como "Arte" é assegurada, comportando necessariamente essa classificação um juízo de valor que serve também para "separar águas" e, portanto, distinguir, e distanciar, um vasto universo de "obras de segunda", "réplicas" e "não-arte". Por outras palavras, o padrão que antecede o reconhecimento da arte maior serve também de ponto de referência hierárquico para uma distinção entre centros e periferias ${ }^{1}$ e para classificações como arte menor, artes menores, arte popular ou arquitectura vernacular.

A revisão da história da arte e da arquitectura pela crítica pós-colonial, bem como a insistência em enfoques mais antropológicos - isto é, procura de narrativas inclusivas e verdadeiramente globais (uma world art history) -, tem demonstrado a obsolescência de critérios de classificação maioritariamente 
eurocêntricos. Tem também contribuído para a própria re-avaliação da história da arte, mostrando, por exemplo, como alguns dos autores da escola formalista que terão estado na base da própria história dos estilos, tiveram afinal uma acção decisiva no combate ao empobrecimento que tais narrativas padronizadas representaram. Basta evocar o nome de Alois Riegl e lembrar o estudo que dedicou à arte industrial tardo romana (Spätrömische Kunstindustrie, 1901), para que a precocidade da luta contra os preconceitos estéticos da historiografia mainstream se torne clara.

Somados os contributos de historiadores como George Kubler nos anos 1960, aos mais recentes esforços de Thomas DaCosta Kaufmann ou David Summers, para citar apenas alguns autores, pode hoje considerar-se que a atenção à arte não-ocidental e à arte das periferias, bem como a crítica às narrativas que Ihes têm sido votadas (vejam-se os trabalhos de J. Elkins, Hans Belting ou Whitney Davis) vêm conquistando um lugar de destaque no campo da história da arte dos nossos dias. Inversamente, o movimento fundamental lançado por Riegl - o de inverter a lógica de periferização que ocorre no centro dos próprios centros - permanece em larga medida desguarnecido. Corrijo: o contributo dos estudos feministas e de género vêm sendo, nesta matéria, decisivo. Todavia, fora desse enquadramento teórico, a periferia dos centros (isto é, a diversidade e as antinomias vividas nos próprios centros) permanece em grande medida uma não-questão. Dir-se-ia que pouco sobra das fecundas noções de impureza e anacronia que, por exemplo, os estudos de Warburg associaram ao renascimento. Resulta daqui que grande parte da produção geograficamente ancorada em áreas de centralidade artística sofre na verdade um brutal apagamento: $\left(1^{\circ}\right)$ por via de uma subalternização pré-determinada pelo elenco de "obras-chave"; $\left(2^{\circ}\right)$ pelo empobrecimento das questões e dos problemas que os historiadores são capazes de equacionar na análise das obras (sejam "obraschave" ou outras). No primeiro caso, lidamos com preconceitos estéticos e com a crença de que a "verdadeira" arte deve ser aferida a partir da conformidade com classificações pré-definidas (os critérios estilísticos). As imagens e os objectos que não se conformam com as classificações estabelecidas mergulham num limbo de obscuridade, e acabam em regra por tornar-se invisíveis. Nos casos em que a importância histórica ou simbólica de obras não-conformes não permite o seu obscurecimento, das duas uma: ou se celebram os magros traços de conformidade à putativa lei geral, em jeito de pequena conquista; ou se decreta a excepção pura e simples (pense-se em Francisco Goya, por exemplo). No segundo caso, lidamos com uma gravosa limitação das possibilidades de análise e discussão, o que implica, para além da reprodução da invisibilidade de importantes faixas da cultura visual e material, o próprio empobrecimento das narrativas centradas nas "obras-chave" (guettizadas numa precária torre de marfim).

Pride in Modesty: Modernist Architecture and the Vernacular Tradition in Italy, de Michelangelo Sabatino, enfrenta ambas as questões enunciadas, compondo um estudo rigoroso e exaustivo que Ihe valeu já amplo reconhecimento (o trabalho foi Best Book Award do Southeast Chapter da Society of Architectural Historians em 2010, Best Book of 2010 Award pela American Association of Italian Studies e Alice Davis Hitchcock Award da Society of Architectural Historians em 2012). Elegendo George Kubler como referência 
teórica do seu trabalho, Sabatino escreve, pois, não para nos remeter amorfamente para dados adquiridos, mas para potenciar o nosso desconforto em relação a eles. Pride in Modesty - expressão que Sabatino recupera dos escritos que, no início dos anos 1930, o historiador da arte Lionello Venturi dirige aos arquitectos nas páginas da Casabella - é um trabalho desenhado numa lógica bottom up, que resgata a importância do olhar para a arquitectura vernacular, do diálogo e do entendimento da arquitectura vernacular, para as discussões do modernismo em Itália. Quer isto dizer que Sabatino trabalha a periferia do centro - o domínio não-erudito do património vernacular, face às diversas faces que o modernismo erudito toma em Itália - abrindo domínios de análise que rompem com as narrativas padronizadas, já que os termos desta relação (entre essa periferia e esse centro) Ihe permitem equacionar a uma nova luz as questões centrais do modernismo. Ou seja, em Pride in Modesty, Sabatino não se limita a tornar visível a longa duração do interesse dos arquitectos pela herança vernacular e a multiplicidade dos debates que esse interesse convocou. Mostra também, no desenvolvimento de cada um dos cinco capítulos que estruturam cronológica e tematicamente a sua abordagem, a centralidade desse interesse e desses debates na cultura arquitectónica italiana entre a Reunificação e o pós-II Guerra Mundial (isto é, o momento coincidente com a eclosão de abordagens arquitectónicas que fazemos coincidir habitualmente com a dissolução do projecto modernista, como as de Aldo Rossi). A herança vernacular surge assim como referência constituinte do modernismo nas suas múltiplas faces. O estudo de Sabatino enriquece, deste modo, o grau de complexidade da análise histórica da arquitectura italiana, e por extensão da arquitectura europeia, em termos que inviabilizam a manutenção de alguns mitos fundadores das narrativas historiográficas da arquitectura moderna. Refiro-me, em primeiro lugar, à séria complexificação que Sabatino impõe à noção de que o modernismo operou uma ruptura radical com a história (discussão que o autor leva ao próprio âmago do futurismo), mas também ao modo como torna evidente a total inadequação de uma associação simplista entre o interesse pela arte e cultura popular e rural, e as expressões folclóricas e nostálgicas próprias da ideologia fascista. Porque a referência à arquitectura vernacular surge muitas vezes associada a posições de resistência, tal filiação ideológica esteve longe de ser hegemónica. No entanto, Sabatino demonstra ainda como, no próprio seio de posições fiéis a Mussolini, houve espaço para a afirmação de um interesse pela arquitectura vernacular eminentemente racionalista e orientado para a valorização de soluções técnicas e construtivas, que foi conscientemente antinostálgico e, nos termos do autor, anti"pitoresco". Complexificações como esta têm enorme relevância. Elas assentam na capacidade de tornar visíveis as contradições que dominam o modernismo e traduzem-se numa abertura enriquecedora (porque finalmente se torna central que, para além de italianos como Giuseppe Pagano, Le Corbusier ou J. L. Sert, coloquem a mediterraneidade no centro das suas pesquisas arquitectónicas). Elas obrigam-nos finalmente a romper com a percepção "pré-cozinhada", ela própria modernista, do modernismo e, portanto, a abandonar a ideia padronizada de uma inovação formal radical, sem referentes, exclusivamente rendida ao funcionalismo. Michelangelo Sabatino orienta essa abertura, esse combate à padronização das possibilidades, a partir de uma recolha empírica exigente. E embora o cerne do debate se concentre evidentemente em Itália, o autor cumpre 
2 K. Frampton, "Towards a critical regionalism: Six points for an Architecture of Resistance". The antiaesthetic essays on Postmodern Culture (ed. H. Foster) - Seattle: Bay Press, 1983, p. 16-30 a promessa que faz na introdução, abrindo a cruzamentos com os desenvolvimentos internacionais da arquitectura moderna, que permitem entrever a extensão europeia e norte-americana das questões analisadas. Que o exemplo da arquitectura portuguesa esteja ausente destes cruzamentos é um facto sintomático e lamentável. É, em primeira instância, sintomático da falta de impacto internacional da historiografia portuguesa, e é lamentável porque o conjunto das matérias debatidas sairia ainda reforçado pela aguda pertinência que tem na observação da cultura arquitectónica portuguesa do século 20, igualmente devedora do olhar sobre o património vernacular - seja nas versões conservadora-folclórica-nostálgica (maioritária) e futurista-racionalista (minoritária), conotáveis com o regime fascista, seja na versão progressista de resistência política a esse regime. A referência ao paralelismo do exemplo português permiteme ainda abrir uma última chamada de atenção: é que, embora em nenhum momento Sabatino a discuta directamente, está implícita, no seu trabalho de revisão da noção padronizada do modernismo na arquitectura, a revisão da ideia consagrada do regionalismo crítico como pedra de toque de um pós-modernismo de resistência ${ }^{2}$. Mostrar a centralidade da arquitectura vernacular no modernismo italiano, como faz Sabatino, tem como consequência directa a moderação do potencial de ruptura atribuído pela historiografia ao conceito de regionalismo crítico. Ou seja, é forçoso que esse potencial seja re-equacionado à luz de orientações de resistência do próprio modernismo, como a atenção à dimensão estrutural da arquitectura vernacular, a valorização de condições topográficas, de luz, do clima, dos materiais em sede de projecto, e o reconhecimento de uma dimensão universal à especificidade cultural de cada região. Ou, nas palavras de Sabatino: "What is key to both of these experiments - northen modernism [Aalto é a referência analisada] versus that of Mediterranean modernism - is the common interest in drawing upon the rethinking the context (site, culture, climate) in order to temper the universal qualities of modernity with regional characteristics embodied in extant vernacular" (p. 13). Em suma, a capacidade da arquitectura contemporânea operar uma síntese consciente destes valores "pós-modernos" surge enunciada no seio deste modernismo pleno, e por isso impuro e diverso, que Sabatino revela em viagem pela arquitectura italiana.

\section{Joana Cunha Leal}

É professora auxiliar do Departamento de História da Arte da Universidade Nova de Lisboa (UNL-FCSH). É subdirectora do Instituto de História da Arte (IHA) da mesma Universidade e responsável pela sua linha de investigação sobre teoria da arte e práticas disciplinares em história da arte. Coedita atualmente o número temático da Revista de História da Arte - práticas da teoria, e prepara um livro sobre o modernismo em Portugal. www.fcsh.unl.pt/faculdade/departamentos/historia j.cunhaleal@fcsh.unl.pt 